九州大学学術情報リポジトリ

Kyushu University Institutional Repository

\title{
Concentration dependence of diffusion coefficients for supercritical carbon dioxide + naphthalene system
}

Higashi, Hidenori

Department of Chemical Engineering, Faculty of Engineering, Kyushu University

Iwai, Yoshio

Department of Chemical Engineering, Faculty of Engineering, Kyushu University

Oda, Tsuyoshi

Department of Chemical Engineering, Faculty of Engineering, Kyushu University

Nakamura, Yuj i

Department of Chemical Engineering, Faculty of Engineering, Kyushu University

他

http://hdl. handle. net/2324/12525

出版情報: Fluid Phase Equilibria. 194-197, pp.1161-1167，2002-03-30. Elsevier バージョン:

権利関係: (C) 2002 Elsevier Science B.V. All rights reserved. 


\title{
Concentration dependence of diffusion coefficients for supercritical carbon dioxide + naphthalene system
}

\author{
Hidenori Higashi, Yoshio Iwai*, Tsuyoshi Oda, Yuji Nakamura, and Yasuhiko Arai \\ Department of Chemical Engineering, Faculty of Engineering, Kyushu University \\ 6-10-1 Hakozaki, Higashi-ku, Fukuoka, 812-8581, JAPAN
}

* Corresponding author

Keywords: diffusion coefficient, equation of state, fugacity, naphthalene, supercritical carbon dioxide

\begin{abstract}
The concentration dependence of diffusion coefficients for naphthalene in supercritical carbon dioxide at 308.2K was measured by a pseudo steady state solid dissolution method. The experimental diffusion coefficients were compared with the calculated results by the Darken equation including a thermodynamic factor and tracer diffusion coefficients of supercritical carbon dioxide and naphthalene. The thermodynamic factor in the Darken equation was determined by using several cubic equations of state. The calculated results by the Darken equation represent the concentration dependence of the experimental diffusion coefficients.
\end{abstract}

\section{Introduction}

Diffusion coefficient in supercritical phase is very important as one of transport properties in the design of supercritical fluid extraction and reaction processes. However, almost all data of diffusion coefficients in supercritical region have been limited at infinite dilution condition and the thermodynamic analysis of diffusion behavior has not yet been fully advanced [1]. In a previous work [2], the concentration dependence for diffusion coefficient of naphthalene in supercritical carbon dioxide was pointed out. The concentration dependence of diffusion coefficients for methane $+n$-decane system in the critical region was reported [3]. Recently, the concentration dependence of diffusion coefficients of lipids in supercritical fluids has been reported [4]. It is necessary to investigate the concentration dependence of diffusion coefficients for the design of the supercritical fluid processes. In this work, the concentration dependence for diffusion coefficients of naphthalene in supercritical carbon dioxide was measured at $308.2 \mathrm{~K}$. The experimental diffusion coefficients were compared with the calculated results by the Darken equation [5]. The thermodynamic factor required in the Darken equation was determined by using several cubic equations of state. 


\section{Experimental}

\section{Materials}

Reagent-grade naphthalene, more than 99.0 mol\% supplied by Nacalai Tesque, was used. High-purity carbon dioxide, with minimum purity of 99.9\%, was supplied by Sumitomo Seika.

\section{Equipment and procedures}

A flow-type apparatus was used to measure the concentration dependence of diffusion coefficients for naphthalene in supercritical carbon dioxide at $308.2 \mathrm{~K}$. The schematic diagram of the experimental apparatus is shown in Fig.1. The apparatus consists of equilibrium and diffusion parts. The equilibrium part was used to adjust the concentration of naphthalene at the inlet of a diffusion cell (14). A pre-equilibrium cell (11) and an equilibrium cell (12) were immersed in a water bath (13). The temperature of the water bath was determined to adjust the concentration of naphthalene. The diffusion cell was set in a water bath (15) regulated at 308.2K. Naphthalene powder was packed into capillaries in the diffusion cell. When supercritical fluid containing naphthalene under the saturated condition at the temperature of the equilibrium part passed through the diffusion cell, naphthalene packed in the capillaries dissolved and diffused into supercritical fluid. A schematic of the capillary in the diffusion cell is illustrated in Fig.2.

The amounts of naphthalene decreased by dissolution were determined from changes of weight of the capillaries by using an electric balance. Diffusion coefficients were determined from the amounts of naphthalene decreased and the elapsed times, as follows:

$$
D_{2}=\frac{\rho_{2}\left(h_{\mathrm{e}}{ }^{2}-h_{\mathrm{b}}{ }^{2}\right)}{2 m_{2} \Delta t\left(\left.C y_{2}{ }^{\text {sat }}\right|_{T_{\text {diff }}}-\left.C y_{2}{ }^{\text {sat }}\right|_{T_{\text {eq }}}\right)}
$$

where $\rho_{2}$ is the packed mass density of naphthalene, $h_{\mathrm{b}}$ and $h_{\mathrm{e}}$ are the distances at the beginning and the end of experiment, respectively. $m_{2}$ is the molar mass of naphthalene, $\Delta t$ is the elapsed time, $C$ is the molar gas density, $y_{2}{ }^{\text {sat }}$ is the saturated solubility of naphthalene in supercritical carbon dioxide, and $T_{\text {diff }}$ and $T_{\text {eq }}$ are the absolute temperature of diffusion and equilibrium parts, respectively.

\section{Correlation}

The Darken equation can be applied to calculate the concentration dependence of diffusion coefficients in supercritical fluid [2]. 


$$
D_{2}=\frac{\left(y_{2} D_{11}+y_{1} D_{21}^{0}\right)}{C \overline{v_{1}}} \alpha
$$

where $D_{11}$ is the self-diffusion coefficient of supercritical carbon dioxide, $D_{21}{ }^{0}$ is the diffusion coefficient of naphthalene in supercritical carbon dioxide at infinite dilution. These were calculated by the Schmidt number correlation proposed by Funazukuri et al.[6]. $D_{2}$ is the mass-fixed diffusion coefficient, $\bar{v}_{1}$ is the partial molar volume of supercritical carbon dioxide. $\alpha$ is the thermodynamic factor defined by the following equation.

$$
\alpha=\left(\frac{\partial \ln f_{2}}{\partial \ln y_{2}}\right)
$$

where $f_{2}$ is the fugacity and $y_{2}$ is the mole fraction of naphthalene.

In the correlation, four cubic equations of state (SRK-EOS [7], PR-EOS [8], Yu-EOS [9, 10] and IML-EOS [11],) are applied to calculate the fugacity, partial molar volume and molar density. The equations of state used in this work are shown as follows:

$$
\begin{array}{ll}
P=\frac{R T}{v-b}-\frac{a}{v(v+b)} & \text { SRK-EOS } \\
P=\frac{R T}{v-b}-\frac{a}{v(v+b)+b(v-b)} & \text { PR-EOS } \\
P=\frac{R T}{v-b}-\frac{a}{v(v+c)+b(3 v+c)} & \text { Yu-EOS } \\
P=\frac{R T}{v-b}-\frac{a}{v^{2}-c(v-b)} & \text { IML-EOS }
\end{array}
$$

The following mixing and combining rules are used for the calculation of the mixture.

$$
\begin{aligned}
a & =\sum_{i} \sum_{j} y_{i} y_{j} a_{i j}, \quad a_{i j}=\left(1-k_{i j}\right) \sqrt{a_{i} a_{j}} \\
b & =\sum_{i} \sum_{j} y_{i} y_{j} b_{i j}, \quad b_{i j}=\left(1-l_{i j}\right)\left(b_{i}+b_{j}\right) / 2 \\
c & =\sum_{i} \sum_{j} y_{i} y_{j} c_{i j}, \quad c_{i j}=\left(1-l_{i j}\right)\left(c_{i}+c_{j}\right) / 2
\end{aligned}
$$

The interaction parameters between unlike molecules, $k_{i j}$ and $l_{i j}$, were best fitted for each equation of state by adopting the solubility data [12] for naphthalene in supercritical carbon dioxide.

\section{Results and discussion}

The experimental results of diffusion coefficients for naphthalene in supercritical carbon dioxide at 308.2K are listed in Table 1 and plotted in Fig.3. The experimental mole fraction of 
naphthalene was defined as follows.

$$
y_{2}=\frac{\left.y_{2}{ }^{\text {sat }}\right|_{T_{\text {diff }}}+\left.y_{2}{ }^{\text {sat }}\right|_{T_{\mathrm{eq}}}}{2}
$$

The experimental diffusion coefficients decrease with increasing the concentration of naphthalene. A large concentration dependence of diffusion coefficients is observed at low pressure and the diffusion coefficients above a certain concentration (an intersection point of both curves) increase with pressure. Similar trends were observed for the diffusion coefficients of methyl oleate and anhydrous milk fat in supercritical carbon dioxide at $313 \mathrm{~K}$ measured by Tuan et al.[4].

The correlated results by several equations of state are compared with the experimental

results in Fig.3. The calculated results of diffusion coefficients with $\alpha=1$ and $C \bar{v}_{1}=1$ are also shown in order to discuss the effect of thermodynamic factor. The calculated results with $\alpha=1$ and $C \bar{v}_{1}=1$ slightly increase with increasing the concentration of naphthalene and show large deviation from the experimental results. The calculated diffusion coefficients by the equations of state decrease with increasing the concentration of naphthalene. The calculated results by using IML-EOS show the best agreement with the experimental data. The estimation of thermodynamic factor is very important to represent the concentration dependence of diffusion coefficients in supercritical fluids.

\section{Conclusion}

The concentration dependence of diffusion coefficients for naphthalene in supercritical carbon dioxide at 308.2K was measured. A pseudo steady state solid dissolution method was applied to measure the diffusion coefficients. The experimental diffusion coefficients were compared with the calculated results by the Darken equation including a thermodynamic factor and tracer diffusion coefficients of supercritical carbon dioxide and naphthalene. The thermodynamic factor in the Darken equation was determined by using several cubic equations of state and tracer diffusion coefficients were calculated by using Schmidt number correlation proposed by Funazukuri et al. The calculated results by the Darken equation with IML-EOS represent well the concentration dependence of the experimental diffusion coefficients. When the diffusion coefficients at infinite dilution and the thermodynamic factor can be estimated, the diffusion coefficient may be predicted under given pressures and temperatures at any concentrations up to the saturated solubility.

\section{Acknowledgments}

We gratefully acknowledge the financial support provided by "Research for the Future" Program (96P00401), The Japan Society for the Promotion of Science, and Grant-in-Aid for 
Encouragement of Young Scientists (10750551), The Ministry of Education, Science Sports and Culture.

\section{List of symbols}

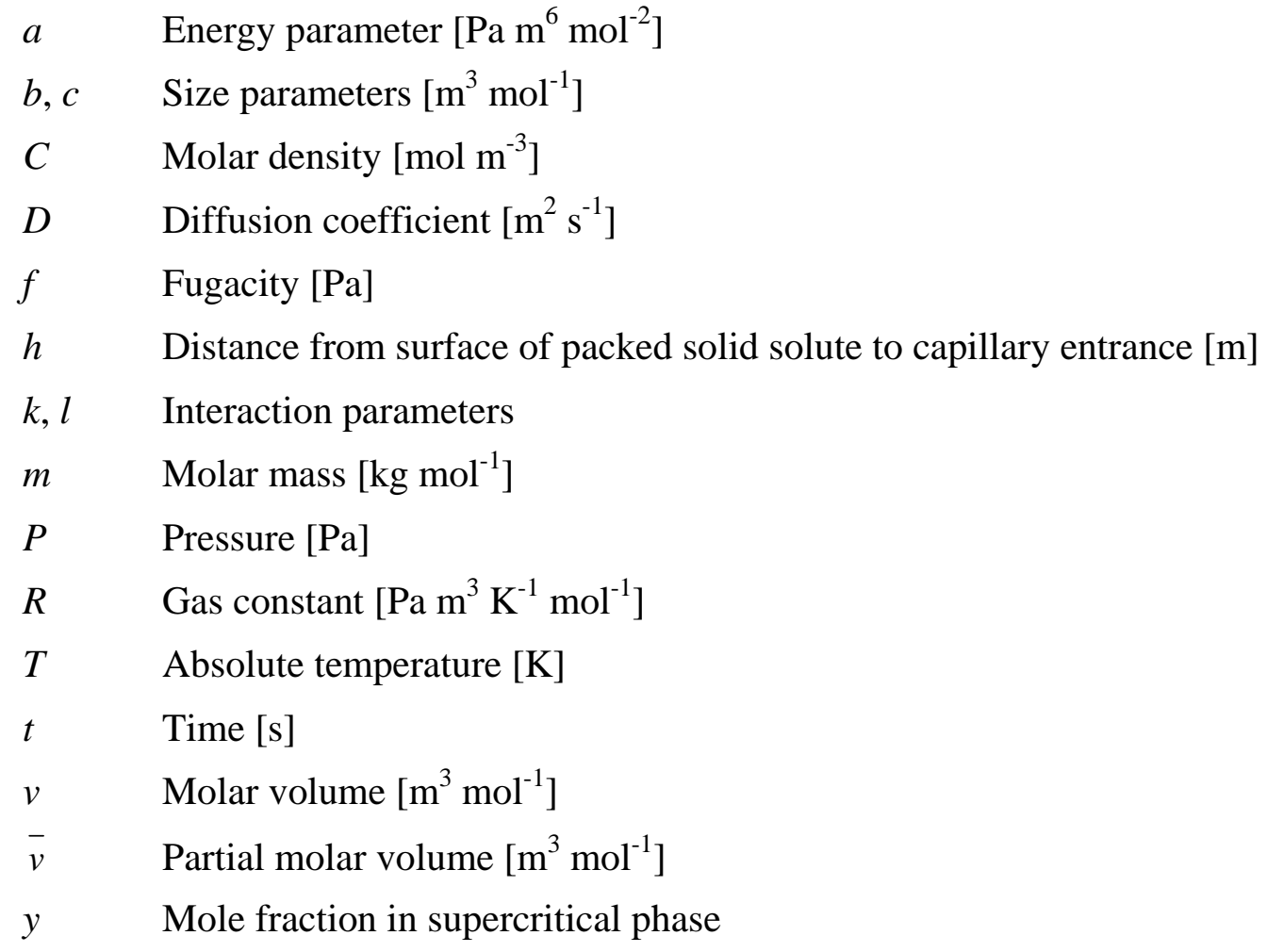




\section{References}

[1] Higashi, H., Y. Iwai and Y. Arai, Chem. Eng. Sci., 56 (2001) 3027-3044.

[2] Higashi, H., Y. Iwai, Y. Nakamura, S. Yamamoto and Y. Arai, Fluid Phase Equilibria, 166 (1999) 101-110.

[3] Dysthe, D.K. and B. Hafskjold, Int. J. Thermophys., 16 (1995) 1213-1224.

[4] Tuan, D.Q., J.A. Zollweg and S.S.H. Rizvi, Ind. Eng. Chem. Res., 38 (1999) 2787-2793.

[5] Darken, L.S., Trans. Am. Inst. Min. Mettall. Eng., 175 (1948) 184.

[6] Funazukuri T., C.Y. Kong and S. Kagei, Int. J. Thermophys., 21 (2000) 651-699.

[7] Soave G. Chem.Eng.Sci., 27 (1972) 1197-1203.

[8] Peng D.Y. and D.B. Robinson, Ind.Eng.Chem.Fundam., 15 (1976) 59-64.

[9] Yu L.M. and B.C.-Y. Lu, Fluid Phase Equilibria, 34 (1987) 1-19.

[10] Yu L.M., B.C.-Y. Lu and Y. Iwai, Fluid Phase Equilibria, 37 (1987) 207-222.

[11] Iwai, Y., M. R. Margerum and B.C.-Y. Lu, Fluid Phase Equilibria, 42 (1988) 21-41.

[12] Tsekhanskaya, Y.V., M.B.Iomtev and E.V. Mushkina, Russ.J.Phys.Chem., 38 (1964) 1173-1176.

[13] Akgerman, A., C. Erkey and M. Orejuela, Ind. Eng. Chem. Res., 35 (1996) 911-917. 


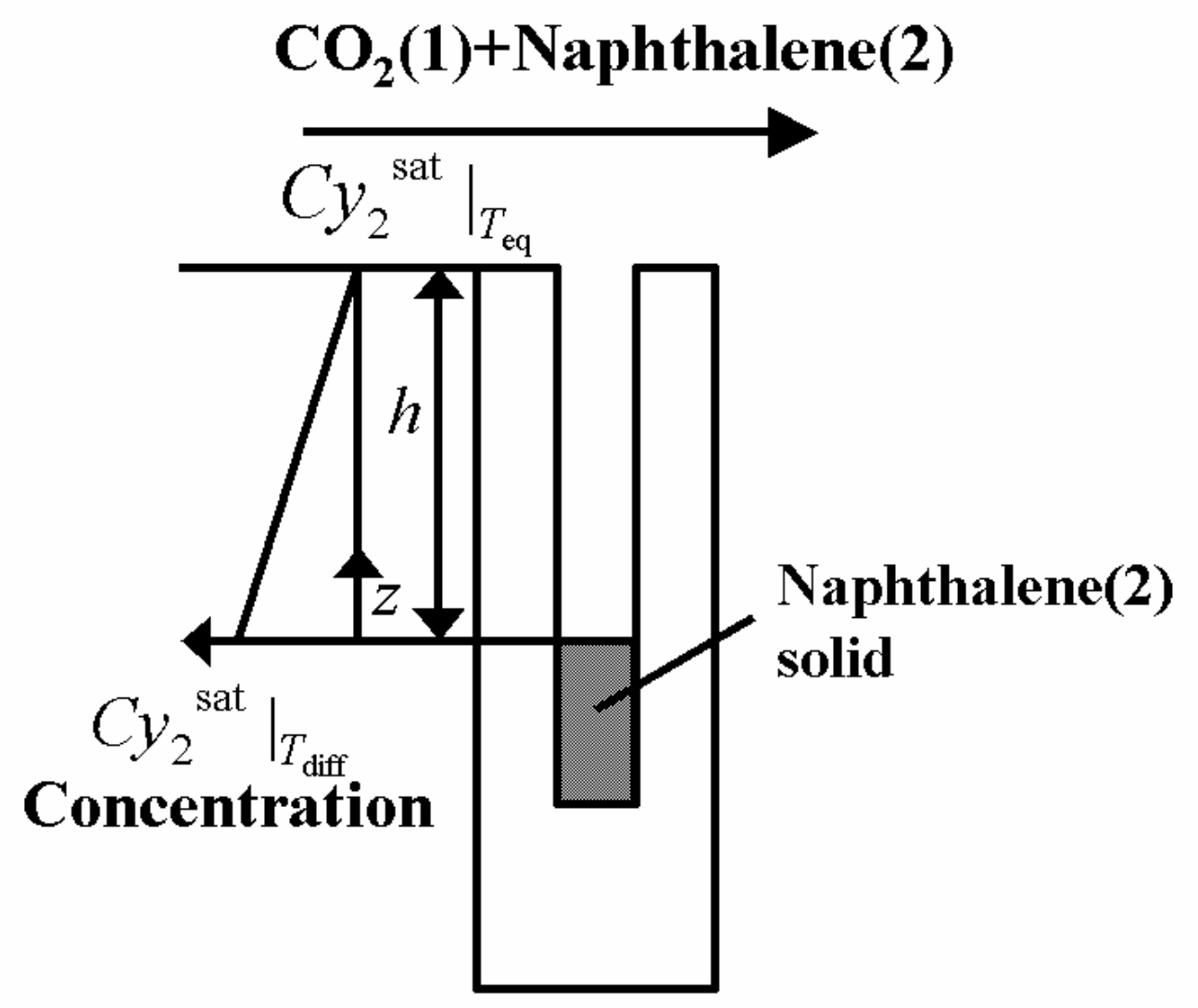




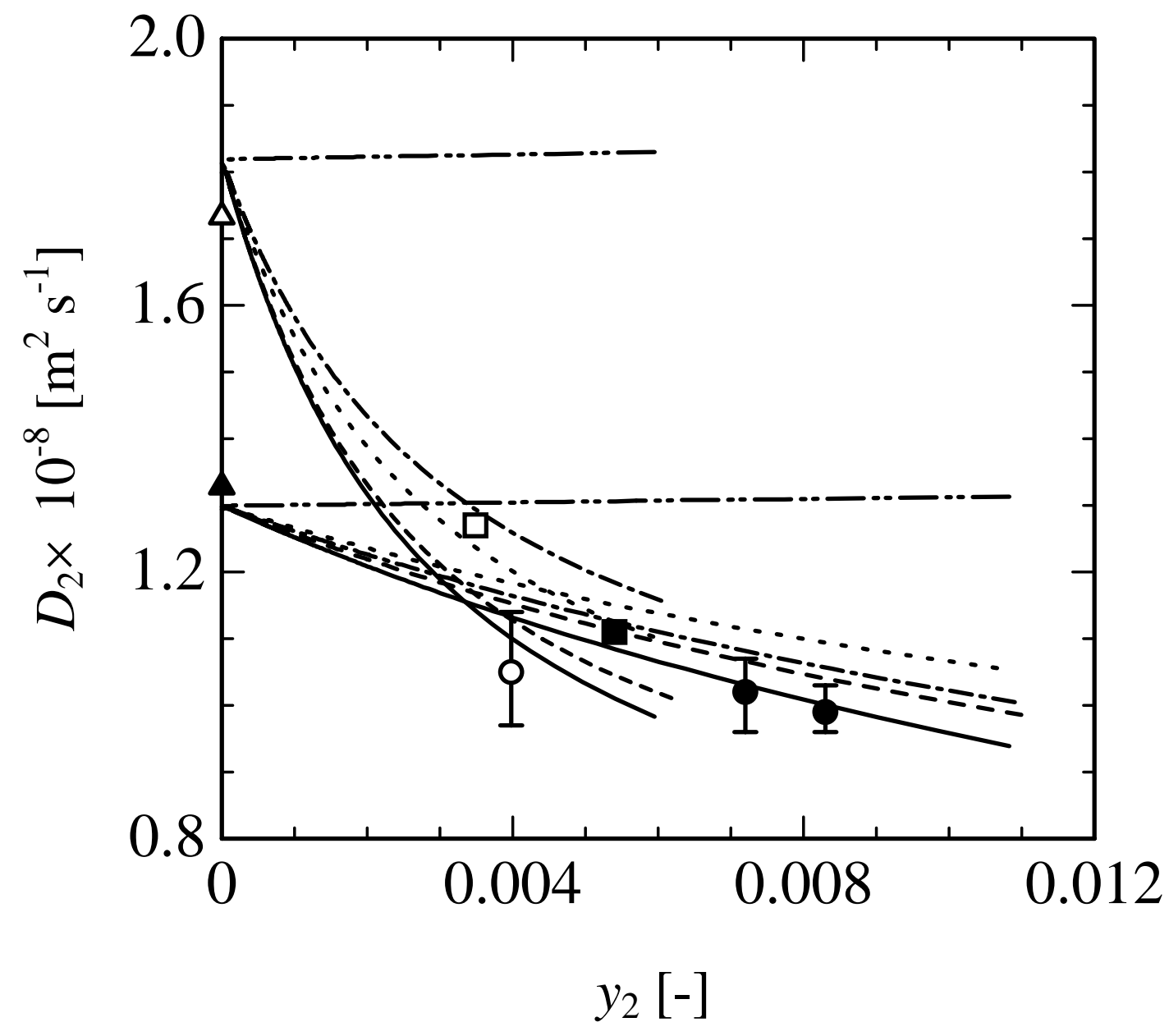


Table 1 Experimental results of diffusion coefficients for naphthalene in supercritical carbon dioxide at $308.2 \mathrm{~K}$.

\begin{tabular}{lc}
\hline$P=8.25 \mathrm{MPa}$ & $\left.y_{2}{ }^{\text {sat }}\right|_{T_{\text {diff }}}=0.00697^{\mathrm{a}}$ \\
\hline$y_{2}[-]$ & $D_{2} \times 10^{-8}\left[\mathrm{~m}^{2} \mathrm{~s}^{-1}\right]$ \\
\hline 0 & $1.73^{\mathrm{b}}$ \\
0.00349 & $1.27^{\mathrm{c}}$ \\
0.00398 & 1.05 \\
\end{tabular}

\begin{tabular}{lc}
\hline$P=10.4 \mathrm{MPa}$ & $\left.y_{2}{ }^{\text {sat }}\right|_{T_{\text {diff }}}=0.0108^{\mathrm{a}}$ \\
\hline$y_{2}[-]$ & $D_{2} \times 10^{-8}\left[\mathrm{~m}^{2} \mathrm{~s}^{-1}\right]$ \\
\hline 0 & $1.33^{\mathrm{b}}$ \\
0.0054 & $1.11^{\mathrm{c}}$ \\
0.0072 & 1.02 \\
0.0083 & 0.99 \\
\hline
\end{tabular}

a : interpolated values by data of Tsekhanskaya et al. [12]

b : inter- and extra- polated values by data of Akgerman et al. [13]

c : interpolated values by data of Higashi et al. [2] 


\section{Figure captions}

Fig.1 Experimental apparatus.
1. Gas Cylinder
8. Precision Pressure Gauge
15. Water Bath
2. Dryer
9. Safety Valve
16. Trap
3. Filter
10. Pre-heater
17. Gas Meter
4. Pressure Gauge
11. Pre-equilibrium Cell
5. Cooling Unit
12. Equilibrium Cell
V1, V3-V10. Stop Valve
6. Feed Pump
13. Water Bath
V2. Back Pressure Regulator
7. Stopper
14. Diffusion Cell
V11.Expansion Valve

Fig.2 Schematic of concentration profile in a capillary.

Fig.3 Diffusion coefficients for naphthalene in supercritical carbon dioxide at $308.2 \mathrm{~K}$.

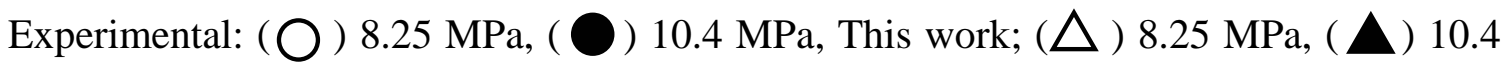
MPa, Akgerman et al.[13]; ( $\square$ ) $8.25 \mathrm{MPa}$, ( $\square$ ) $10.4 \mathrm{MPa}$, Higashi et al.[2]; Correlation by Darken equation: $(-\cdots-\cdots) \quad \alpha=1$ and $C \bar{v}_{1}=1 ;(\square)$ $\operatorname{IML-EOS}\left(k_{12}=0.020, l_{12}=-0.129\right) ; \quad(-\cdots \cdot-\cdot \quad) \quad \operatorname{SRK}-\operatorname{EOS}\left(k_{12}=0.024, l_{12}=-0.171\right)$; ( ……....... ) PR-EOS $\left(k_{12}=0.016, l_{12}=-0.173\right)$; $(---)$ Yu-EOS $\left(k_{12}=0.015, l_{12}=-0.190\right)$. 